\title{
Autonomy, welfare and the treatment of AIDS
}

\author{
Roger Crisp St Anne's College, Oxford
}

\section{Author's abstract}

Many AIDS-related issues are polarised. At the social level, civil rights or liberties are seen as being in conflict with general utility, and an analogous distinction is often assumed to exist at the one-to-one, individual level at which doctors work. In this paper the latter form of the distinction is argued to be false. By seeing autonomy as part of welfare, doctors can think more directly about such issues as paternalism, confidentiality, and consent. A number of these issues are discussed in the light of the revised conception of welfare, in the form of simplified case studies.

\section{Two principles}

In most parts of the world, the vast majority of doctors have yet to treat large numbers of patients suffering from AIDS. Unfortunately, this situation is unlikely to continue. Many people are already infected with the HIV virus, and it is spreading at an alarming rate (1). It will be of small consolation to these doctors that AIDS does not raise any fundamentally novel ethical issues. For the old dilemmas will seem quite as intractable in their new context. Indeed, some of the characteristics of AIDS - its prognosis and transmission, for example - seem to emphasise the starkness of the moral options open to those called upon to treat its sufferers.

In this paper, I shall examine six important areas in which HIV and AIDS infection raise problems for the individual doctor. There are, of course, others. And AIDS gives rise also to questions in the spheres of law and social morality (2). I hope that what I say may be relevant to these other issues, but it is not my intention to address them directly.

Ethical views are usually expressed from some perspective, be it Christian, Marxist, feminist, or whatever. Two perspectives which dominate much ethical thought at present are those of liberalism and utilitarianism. These perspectives themselves rest on particular principles, liberalism on what I shall call the Autonomy Principle, and utilitarianism on the Welfare

\section{Key words}

AIDS; autonomy; welfare; doctors' decisions; rights; liberty.
Principle. The principles may be stated loosely as follows:

The Autonomy Principle. One ought to respect the rights of autonomy and liberty.

The Welfare Principle. One ought to maximise welfare.

I shall call a person who advocates the former principle a liberal, and the latter a utilitarian. One of the striking things about these principles is that many of us, including many doctors, feel attracted by both. On the one hand, we want to respect the rights of individuals to determine their own lives, and, on the other, to fulful our duties of benevolence towards either the individual herself, or other individuals (3). Often it is this that gives rise to moral dilemmas in particular cases. For the two principles appear on occasion to counsel inconsistent courses of action.

In the cases I am about to discuss, I shall illustrate the position on each of a liberal and a utilitarian, as I have described them (4). What is remarkable is that their practical conclusions are quite opposite in every case. I shall deal with each area in the form of a casestudy. This is not only for the sake of clarity, but for a further reason which I shall later make clear. The cases, and indeed the positions taken on them, are over-simplified - and to that extent artificial - in order to emphasise their salient features.

\section{Some problems}

(i) Paternalism. Alan is told by his doctor that the results of the tests he consented to have been returned, and that he is not, as far as she knows, HIV-positive (5). Alan is known by the doctor to be at risk. He is an intravenous drug-user and engages in a great deal of casual gay sex. The doctor informs him of the dangers and how to avoid them, but Alan refuses to change his lifestyle. He tells the doctor that he intends to continue both to practise unsafe sex and to share needles.

The liberal position. Alan has a right to determine how his own life should go. Once he has been informed, he should not be prevented in any way from continuing as before.

The utilitarian position. The doctor is required, in Alan's own interests, to try to prevent him from 
engaging in these life-threatening activities. She could, for example, approach those close to Alan and ask them to dissuade Alan from continuing.

(ii) The right to ignorance. Betty has been ill, and asks her doctor to carry out some blood-tests to ascertain the nature of her illness. She expressly requests that, should the tests show that she has AIDS, the doctor not tell her. The tests indicate that she has AIDS.

The liberal position. Betty has a right not to be informed of things which she does not wish to know. The doctor should not violate this right.

The utilitarian position. Betty cannot be cured of the disease, but there is treatment available which can alleviate its symptoms. For her to receive that treatment, it is necessary that she be told. If she is not treated, her own welfare and that of her friends and relations will be damaged for no good reason. There is also the possibility of risk to third parties.

(iii) Confidentiality. Colin, a bisexual married man, is advised by his doctor that he is HIV-positive. The doctor asks him whether he intends to inform his wife, or to practise only safe sex with her. Colin tells the doctor that he intends to do neither, and that he will continue to engage in unprotected sex with his wife.

The liberal position. Doctors must not breach their professional obligations of confidentiality. The doctor may attempt to persuade Colin to change his mind, but on no account must he inform the wife.

The utilitarian position. If Colin refuses to yield to persuasion, his wife should be informed by the doctor as soon as possible.

(iv) The rights of practitioners. Doreen, an intravenous drug-user, was warned by her doctor not to share needles. She ignored this advice, and is now HIVpositive. The doctor feels that Doreen brought the disease upon herself, and also that he is not called upon to risk his own life for his patients. Therefore, he wishes to reject Doreen as a patient.

The liberal position. Other things being equal, the doctor has a right to decide whom he shall treat, just as a publican has a right whom he shall serve. The doctor may therefore refrain from treating Doreen, even if we think this to be callous.

The utilitarian position. What people deserve is irrelevant here. The doctor must act in the interests of his patient, unless the risk is very great. It is not great. Therefore, Doreen should be treated by the doctor.

(v) Consent. Eric's doctor suspects that Eric may have anaemia, and Eric therefore agrees to a blood-sample being taken. After Eric has left the surgery, the local health authority contact the doctor to ask whether they may use the blood-samples taken at the surgery that day in random and anonymous blood-testing for HIV.
The tests are aimed solely at obtaining statistics concerning the spread of the virus in the area.

The liberal position. Eric has a right over his body, and its parts. If the doctor believes that the blood should be released to the authority for testing, Eric must be informed and his consent obtained.

The utilitarian position. Eric will not know that his blood has been tested, and because the tests are randomised and anonymous, no harm can come to him even if he is HIV-positive. Therefore, the doctor can agree immediately to the health authority's request.

(vi) The rights of patients. Fiona is a general practitioner, who has become HIV-positive through sexual contact with a bisexual man. Although she is aware that if they knew of this many of her patients would prefer to register with another doctor than be treated by her, she intends to continue to practise without informing her patients of her condition.

The liberal position. Patients have a right to be informed of any condition of their doctors which may threaten their lives. Fiona should either cease to practise, or inform her patients so that they can make an informed choice.

The utilitarian position. The patients are very unlikely to be harmed if treated by Fiona. She will certainly suffer greatly should she have to cease practising, or see the number of her patients fall drastically. Therefore, she should continue to practise, and keep her condition hidden for as long as possible.

These, then, are the areas on which I want to focus. Clearly, some moral issues arise in more than one area. Consent, for example, is relevant not only in the case of Eric, but in every other case besides that of Doreen. But in general the various problems in each area are sufficiently distinct to justify my differentiating them as I have.

\section{Possible solutions}

The cases I have discussed will present themselves to most people as moral dilemmas. This is because, as I noted, most of us are neither pure liberals nor pure utilitarians. But this puts us in a quandary whenever the two principles - the Autonomy and Welfare Principles - conflict. Sometimes, of course, they will not. Often welfare can be maximised most efficiently by respecting a person's autonomy ('only she knows what she really wants'). But in the six cases above, there is a conflict. What is the concerned doctor to do in such cases?

One suggestion might be that she reflect upon which principle she wishes to hold on to, and which to reject. She must decide whether, in fact, she is a liberal or a utilitarian, just as a football supporter, who has cheered equally loudly for United and City throughout the season, must finally make up her mind at which end of the ground to stand in a local Derby. 
This policy would have at least one desirable consequence. Moral decision-making would be far less taxing. The doctor has just to work out what her chosen principle requires in each case, and carry it out, ignoring the opposing principle altogether. But it is clear also that this kind of decision-making pays for its simplicity the price of insensitivity.

It often helps, when examining moral principles, to apply them to the situation of a single individual, at the prudential or intrapersonal level. It enables one to focus one's intuitions on the values underlying the principles, and to avoid complications arising from trade-offs or their prohibition in cases involving more than one person, at the interpersonal level.

First, then, consider what it would be like for me to run my life according to the Autonomy Principle. Most of the time, all would go well. I would presumably use my autonomy to further my welfare (allowing the Welfare Principle lexical posteriority - that is, application once the Autonomy Principle has been respected), and a satisfactory level of welfare seems anyway to be a necessary condition of autonomy. But there are times when strict application of the Autonomy Principle is likely to make my life go worse. For example, in some areas of my life, I may wish to hand over control to other people, in order to avoid anxiety to myself. I may have atrocious taste in clothes, and ask you to choose what will suit me best. If I do not do this, I will spend much of the time when I am in public fretting over my appearance. Or I may wish to deepen a close personal relationship. This would require assuming certain obligations which would diminish my autonomy, even if only in a small degree. But my life would go better were I to deepen the relationship.

Now consider a life lived on the Welfare Principle. Again, of course, in most cases there would be no conflict with the directives of the Autonomy Principle. I am generally in the best position to decide what is best for myself, and handing over too much control to others can be dangerous. They may have in mind not benefiting me, but using me for their own ends. Again, however, in certain cases the Welfare Principle looks quite mistaken. Imagine that you are twenty-two years of age. You are approached by a committee of the elder members of your family. They tell you that they are willing to take over the running of your life. They will give you the right job, introduce you to the most interesting people, supply you with the best books to read, and so on. Looking back on your life so far, and all the wrong turns that you have made, you realise that the committee, the members of which you trust implicitly, is certain to run your life better than you can.

I think that you would be foolish to accept this proposal, even if the committee were to run your life more efficiently. For a person's life to be well worth living requires that to a substantial degree the life be led by that person and not by others. The Welfare Principle alone will not suffice in the prudential sphere.

This example can guide us towards a solution of the problems raised by the conflicts that arise between the recommendations of the two principles in particular cases. We should see autonomy as itself part of welfare. It is not just having a good job, fascinating friends, and enjoyable hobbies that make my life worth living, but the very leading of that life itself. Both the liberal and the utilitarian, as I have characterised them, have an impoverished conception of welfare. This leads the liberal to exaggerate the value of autonomy, and the utilitarian to ignore it. But a richer conception of welfare, in which control over the central parts of one's life features as itself a substantive value, enables one to avoid the apparent conflict.

The liberal and the utilitarian may remain unconvinced by my argument for a richer conception of welfare. Adopting the lines taken by, on the one hand, classical utilitarians, and, on the other, most modern utilitarians, they may claim that welfare is either a certain mental state, such as pleasure, or a number of mental states, such as pleasure and aesthetic contemplation; or the fulfilment of desires, actual, or corrected in the light of rationality. For a conception of welfare to play any important part in moral thinking requires that values be commensurable, in order that trade-offs of one good for another can be made in particular cases. The objection to my claim is that I have set up autonomy as itself an intrinsic value, a thing good in itself, an end. And because I refuse to take a reductionist stance towards autonomy (explaining its value in terms of mental states and/or the fulfilment of desire), I am left with unacceptable incommensurabilities which will paralyse moral thinking (6).

One rejoinder here might be to accept full incommensurability of values, but deny that this rules out moral thinking (7). But this strikes me as an unhappy response. For if autonomy and, say, pleasure are incommensurable in the way that, for instance, the height and smell of a rose are incommensurable, it is indeed hard to see how we could engage in serious moral thinking. Moral thinking, including that of doctors, has to proceed on the assumption that there are certain answers to moral questions which are better than others. Whereas if the Autonomy and Welfare Principles never make any contact, we shall be left in the same quandary as that which the richer conception of welfare was to help us avoid.

A more promising reply would be to question the very assumption on which the objection rests. This is the view that, if one argues that there are several things which are valuable in themselves, comparisons are impossible.

The nature of practical reasoning itself throws this view into doubt. Consider another prudential case. I have received my pay-cheque, and am deciding on what to spend it. My alternatives are a bathroomheater, or a series of Spanish evening classes. What happens when I am deciding? Surely not that I reduce 
the alternatives to some common substratum, such as pleasure or the fulfilment of my desires, and then balance them to find the more weighty? Rather, I adduce considerations in favour of each alternative: the bathroom was freezing last winter; I have a cold coming on; I profited greatly from learning Italian two years ago; I have nothing better to do on Wednesday nights; and so on. Then, in the light of these considerations, I judge the alternatives and come to a decision. If we agree that this analysis of practical reasoning is, for the most part, accurate, then the assumption on which the objection rests must be false. And if my prudential thinking is not paralysed by a pluralism of values, then I see no reason why my moral thinking should be.

\section{Moral decisions}

I have suggested, then, that with a richer conception of welfare, including autonomy as itself a substantive value, we may be able to move towards a resolution of certain moral dilemmas which are likely to face those involved in the treatment of HIV and AIDS. Let me now briefly return to the six areas of conflict I described, in order to see whether there is substance in the suggestion.

(i) Paternalism: is the doctor to prevent Alan from risking his life?

Bearing in mind the committee example above, it may seem obvious that the liberal position on this issue is correct. But this would be too swift. In that case, you were asked to surrender control of your life for all time. If we take a more global view of autonomy, seeing it as a value in a temporally extended fashion, we can see that it can sometimes be restricted for the sake of autonomy itself. I may restrain you temporarily from committing suicide, and later you may thank me for doing so. For you have a life you would not otherwise have had, over which you have control. It may be that the doctor should interfere, at least temporarily. The decision must depend on the further facts of the case, which the doctor must do her best to ascertain. Is Alan angry at the virus, and thus not thinking straight at the moment? Or is his decision a reasoned one - his identity is so bound up with the way he lives that he feels that to change his life would change his identity? If the latter is the case, then I believe that Alan's autonomy should be respected. Even in the former case, the doctor should take steps to interfere warily and only after much reflection.

(ii) The right to ignorance: should Betty be told that she is suffering from AIDS?

In certain cases of cancer, doctors argue that the patient should not be told of her illness on the ground that it lessens the chance of recovery. In the case of AIDS, however, there is no chance of recovery. But patients can be kept well to some degree in cases of both terminal cancer and AIDS. Effective treatment requires some understanding by the patient of the nature of the disease, in order that she may participate in active interventions. For example, treatment using the drug Zidovudine (AZT) would prolong Betty's life and improve its quality. Also relevant is that with appropriate support and counselling patients usually adapt well to their illness, even when they have previously taken a very negative attitude towards it. Given all this, and taking into account also the facts that Betty's accelerated deterioration is likely to cause great upset to her family and friends, that she may put others at risk, and that she will find out anyway that she has the disease, I am inclined to say that she should be informed - tactfully and gently - of the result of the tests (8).

(iii) Confidentiality: should Colin's wife be informed?

When we contemplate the position of this couple in isolation from the rest of society, it is quite clear that the wife should be told. Colin's autonomy is important, but not to the extent that he should be enabled to put the life of another person at serious risk. But there is a further (utilitarian) argument in favour of confidentiality, based on a broader view of the case (9). If it becomes known that doctors breach confidentiality, it is said, other people with AIDS will be more reluctant to come forward, and this will cause more harm overall. This argument, of course, rests on certain empirical assumptions. And these assumptions are almost certainly false. First, doctors will be called upon to breach their obligations only in a very few cases, where they have been unable to persuade the patient to do her duty. (Doctors are already permitted or required to do this in certain cases.). Second, there is still a strong self-interested reason to motivate people with AIDS to visit doctors, even if they are worried about breaches of confidentiality. Dying from AIDS is extremely unpleasant, and dying without professional medical care even more so. (Of course, this latter reason will not apply to those who are merely HIVpositive.)

(iv) The rights of practitioners: should the doctor treat Doreen?

It might be said that Doreen will suffer no harm by being transferred to another doctor, whereas if the doctor is required to treat her, his autonomy will be violated. Both of these claims are incorrect. The role of doctors as pillars of the community should not be ignored. Doreen may well hold her doctor in high regard, as a respected and sympathetic figure. To be rejected by him when she is in dire need of comfort and support could be very damaging. But what of the doctor's autonomy? Medicine is a profession, and becoming a professional requires one to surrender one's moral autonomy in the sphere of the profession in order to place oneself under the special obligations of the profession. It is unlikely to be morally appropriate for a doctor to act in a way inconsistent with his professional duty. He exercised his autonomy in entering that profession, and it is partly doctors' readiness to abide by the requirements of their 
profession that makes them so valuable to the community. Now it may be said that even a doctor is not required to give up his life for his patients. There is much in this. But the doctor here is not being asked to give up his life. He is being asked to place his life at some risk. But his professional obligations of course require him to put his life at some risk. Here the risk of infection is so small, especially if the doctor takes precautions, that it is clear that he is obliged to treat Doreen.

\section{(v) Consent: can Eric's blood be tested?}

Autonomy does involve certain rights of selfownership. A doctor cannot remove important organs from Eric's body against his will in order to benefit a number of others. But do these rights extend to small amounts of blood which have anyway been transferred to others? I think not. If I find that my hairdresser has been sweeping up hair-clippings at the end of the day, washing them, and using them as stuffing for cushions for his dog, it would be absurd for me to insist that he seek my permission first. Whatever happens to the hair-clippings, my autonomy remains unviolated. The same applies with the blood-sample, as long as (a) the tests are randomised and anonymous (to protect Eric's rights to confidentiality and ignorance); and (b) Eric has not specifically requested that such tests not be carried out. It is worth pointing out that it is already common practice for blood to be tested in this way for various other infections. It might be argued that Eric's consent should anyway be sought (10). But if his autonomy will not be violated by the tests, this will be merely a waste of time and resources which could be put to better use elsewhere. There are also the social benefits accruing from greater knowledge of the epidemiology of the disease to be considered.

(vi) The rights of patients: should Fiona tell her patients that she is HIV-positive?

It will help to clarify the issues in this case if we imagine another, similar in all relevant respects except that the patient is objecting to the doctor because she is black. We should not be any more inclined to sympathise with this patient's wish if she claims that black doctors are more likely than white doctors to have contracted a tropical disease, and thus to be putting her life at risk. The probabilities here are so small as to expose what is said as a patent rationalisation of prejudice. Given that there is sufficient public education about HIV and AIDS, those of Fiona's patients who deserted her would be acting out of prejudice. And to say that autonomy requires that one be able to harm another out of prejudice is mere cant. Fiona may continue her work without informing her patients. Her condition is not their business. If she were involved in invasive surgery, however, the case would be different. Here the perceived risk would be closer to the actual risk, and, since the risks are at present difficult to assess, I am readier to say that Fiona should either refrain from carrying out such surgery or make clear her position to the patient.

Using the richer conception of welfare, then, I have been able to approach in a more balanced way the problems raised. I do not expect the reader to agree with the substance of all the proposed solutions above. What I am attempting primarily is to suggest a methodology which will not ignore the importance of either autonomy or welfare.

I want to conclude with a general point about our approach to practical moral questions. This point is especially relevant to those called upon to treat people with AIDS. For they will, as I have said, meet old problems in new guises.

My aim in this paper has been the modest one of removing an obstacle to moral thinking. I do not expect that a doctor will be able to take the notion of welfare I have advanced and use it as just another tool of the trade, like a stethoscope. Moral decisions are of such complexity that they are not made, and cannot be made, solely on the basis of a number of explicit, stateable principles. Doctors should well be able to appreciate this, for it seems that there is a strong analogy between their methods of diagnosis and moral decision-making (11). Doctors take the symptoms of the patient as considerations, and judge in the light of them. This capacity to judge in such spheres is found in what Aristotle calls aisthesis - 'perception', or 'sensitivity' (12). Medical sensitivity comes with medical experience. We are likely to find less practised doctors consulting more experienced colleagues on unusual cases. Likewise, the capacity to make moral decisions is partly a matter of sensitivity to relevant considerations. And moral aisthesis also comes through experience (13). This was my second reason for employing case studies above. By contemplating hypothetical cases, elaborating upon them, and discussing them with others, doctors will sharpen their sensitivity to the actual moral considerations in the dilemmas which are bound to occur in their everyday practice (14). AIDS, being so new and so terrible, poses a great challenge to not only the medical but the ethical capacities of doctors. Serious moral thinking about the disease can serve only to prepare them for the deluge of suffering they are about to face.

\section{Acknowledgements}

I owe many of the thoughts in this paper to discussions with James Griffin. I am grateful for comments on earlier drafts to Brenda Almond, Anthony Crisp, Anthony Grayling, Gabriele Taylor, and two anonymous referees for the fournal of Medical Ethics.

Roger Crisp BPhil MA DPhil is Lecturer in Philosophy, St Anne's College, Oxford.

\section{References and notes}

(1) The World Health Organisation states that 73,000 cases 
of AIDS had been reported by February 1988. It estimates that between five and ten million people are infected with HIV. Connor S, Kingman S. AIDS cases set to grow fifteen-fold. New scientist 1988; 1641:23-24. Scientific advisers have told the British Government to expect between 10,000 and 30,000 cases of AIDS by 1992. This means that the problem could be fifteen times greater in four years.

(2) Some of the legal issues are discussed in Kirby M. AIDS legislation - turning up the heat? Fournal of medical ethics $1986 ; 12: 187-194$. Some social issues are covered in Mohr R. AIDS, gays, and state coercion. Bioethics 1987; 1:35-50. See also Almond B, ed. AIDS: a moral issue. London: Macmillan, forthcoming 1989.

(3) The most well-known exponent of the two principles contemporaneously is, of course, J S Mill, in his On liberty and Utilitarianism. Many efforts have been made to find a consistent position in Mill. A good survey is Strasser M. Mill and the utility of liberty. Philosophical quarterly 1984; 34:63-68. See especially Gray J. Mill on liberty: a defence. London: Routledge and Kegan Paul, 1983.

(4) The names I have attached to each problem are not intended to favour either the liberal or the utilitarian perspective. They are merely those most commonly used to demarcate the sphere of discussion. Nor am I to be interpreted as claiming that any 'real' liberal or utilitarian must advocate the positions in the text. The positions as well as the cases are simplified to bring out the main point of my argument.

(5) One must be clear as to the distinction between HIV (the Human Immunodeficiency Virus) and full-blown AIDS (Acquired Immune Deficiency Syndrome). The ethical implications of any particular case may well depend on this distinction.

(6) I argue the case for non-reductionism in Quality of life in health care. In: Gillett G, ed. Medicine and moral reasoning. Oxford: Oxford University Press, forthcoming 1989.

(7) See Berlin I. Two concepts of liberty. In: Four concepts of liberty. Oxford: Oxford University Press, 1979; Taylor C. The diversity of goods. In: Sen A, Williams B, eds. Utilitarianism and beyond. Cambridge: Cambridge University Press, 1982.

(8) See Strasser M. Mill and the right to remain uninformed. Fournal of medicine and philosophy 1986; 11,3:265-278.

(9) See Gillett G. AIDS and confidentiality. Fournal of applied philosophy. 1987; 4,1:15-20. Reprinted in Almond B, ed. See reference (2).

(10) Gillon R. Testing for HIV without permission. British medical journal 1987; 294: 821-823.

(11) The analogy is an ancient one. It is considered by Plato (see for example Republic, 331el-334b6); and adopted by Aristotle (see for example Nicomachean ethics VI.1, 1138b21-32).

(12) Nicomachean ethics II.9, 1109b21-23; VI.8, 1142a23-30.

(13) Nicomachean ethics II. 1, 1103a31-b2; VI.8, 1142a11-20; VI.11, 1143b6-14; X.9, 1181a19-bl2. See also McDowell J. Are moral requirements hypothetical imperatives? Proceedings of the Aristotelian Society, supplementary vol $1978 ; 52: 13-29$. Virtue and reason. The monist 1979; 62,3:331-350. The role of eudaimonia in Aristotle's ethics. In: Rorty A, ed. Essays on Aristotle's ethics. Berkeley and Los Angeles: University of California Press, 1980. Aesthetic value, objectivity, and the fabric of the world. In: Schaper E, ed. Pleasure, preference and value. Cambridge: Cambridge University Press, 1983.

(14) I discuss the ethical training of those who treat the terminally ill in A good death: who best to bring it? Bioethics 1987; 1,1:74-79.

\section{News and notes}

\section{Society for Health and Human Values Meeting}

The Society for Health and Human Values is pleased to announce that its 1989 annual meeting will take place October 26-29, 1989 in Washington, DC. For further information about the meeting, contact
John Moskop, PhD, Department of Medical Humanities, East Carolina University School of Medicine, Greenville, North Carolina 27858-4354, telephone: (919) 551-2797. 